\title{
Distributed Epistemic Responsibility in a Hyperconnected Era
}

\author{
Judith Simon
}

\section{Introduction}

To explore what being human in a hyperconnected reality could mean, we may start with Hannah Arendt's challenge to reconsider "the human condition from the vantage point of our newest experiences and most recent fears" (Arendt 1958) as was suggested in the background note to the ONLIFE Initiative. A core experience in our contemporary socio-technical lifeworld - often resulting in fear-concerns responsibility and accountability: namely, the difficulty to attribute responsibility and to locate accountability in ever more distributed and entangled socio-technical systems. Think small: about the difficulties of finding and reaching the person to make responsible in case of a non-functioning internet connection? Think big: who is responsible - accountable and liable - for the financial crisis?

Computer technology and ICT in particular has deepened and aggravated these issues. Think of artificial agents, search engine algorithms, the personal data handling of social networking sites; think of drones, robots in military and healthcare or unmanned vehicles, think of algorithmic trading: who is responsible and especially if things go wrong-who is to blame: designers, users, the technologies or rather the distributed and entangled socio-technical systems? What are the normative implications and who is in charge and able to set the regulative frameworks?

On the one hand these are issues to be tackled by policy makers: regulations are needed for algorithmic trading, for drone deployments, for the design of electronic patient record systems - and for an overabundance of constantly emerging new issues related to the attribution or assumption of responsibility in socio-technical environments. On the other hand, there are actions and decisions to be taken by each and every one of us in our daily lives. When meandering on the Web, where can

\footnotetext{
J. Simon $(\bowtie)$

Institute of Philosophy, University of Vienna, Vienna, Austria

e-mail: judith.simon@univie.ac.at

Technologies in Practice Group, IT University Copenhagen,

Copenhagen, Denmark 
we place trust and where should we be vigilant? How can we and how should we assume responsibility ourselves and how can we attribute it to others?

In this contribution I specifically focus on the responsibilities in processes of knowing. I argue that concerning these so-called epistemic responsibilities we are also facing new challenges in a hyperconnected reality, which require thought and action both on a macroscopic level as well as on a microscopic level. While reconsidering received notions of responsibility, it is therefore advised to distinguish two relevant perspectives:

1) the individualistic perspective, focusing on individuals acting as knowers within increasingly complex and dynamic socio-technical epistemic systems. The leading question here is: what does it mean to be responsible in knowing?

2) the governance perspective, focusing on the question how systems and environments should be designed so that individuals can act responsibly. The leading question here is: what does it take to enable responsibility in knowing?

Clearly, these two perspectives are related. Actors acting within environments shape these environments through their action just as much as those with an explicit governance mandate are themselves often part of the environments they intend to design and govern. Nonetheless, the distinction enables fleshing out different tasks and duties - different responsibilities - related to either acting within systems or designing and governing systems.

\section{Knowing Today}

Our ways of knowing, be it in research or in everyday-life are on the one hand highly social: much of what we know, we know through the spoken or written words of others; research consists not only in collaboration, but also in building upon previous knowledge, in communicating information, in communal quality assessment of scientific agents or content (e.g. peer review), etc. On the other hand, technology, particularly information and communication technologies mediate and shape these practices of knowing to profound extends. We check Wikipedia to find information about a city we plan to visit or some information about a historical incident, we rely on search engines to deliver relevant information on a specific topic, we use ratings of other agents explicitly to assess the quality of products before buying them or implicitly by accepting the ordering of search results or recommendations. Thus, contemporary epistemic practices have to be conceived as socio-technical epistemic practices.

Within these entangled socio-technical processes of knowing, we rely in numerous more or less transparent ways on other agents, human agents as much as non-human agents, infrastructures, technologies. However, what does this mean for the two main issues addressed in this paper, i.e. what are the implications of this socio-technical epistemic entanglement for (1) being responsible in knowing 
(individual perspective) and (2) for enabling responsibility in knowing (governance/design perspective)?

While the former issue is of relevance to each and every one of us, the latter is of special concern for policy makers. Particularly interesting cases for the governance perspective are the so-called Responsible Research and Innovation initiatives which have been proposed by several national research councils in Europe (e.g. in the UK, the Netherlands and Norway) as well as by the European Commission.

\section{Responsible Research and Innovation}

The Responsible Research and Innovation strategy of the European Commission is part of the prospective EU Framework Programme Horizon 2020 as a successor to the Science in Society strand of the current Framework Programme FP7. By combining the word responsible with research and innovation as two particularly knowledge-intense domains, it could be expected that RRI will deliver at least some answers to the before mentioned challenges regarding responsibility—particularly epistemic responsibility - in a hyperconnected era.

So what is RRI about? According to a recent leaflet by the European Commission: "(r)esponsible Research and Innovation means that societal actors work together during the whole research and innovation process in order to better align both the process and its outcomes, with the values, needs and expectations of European society. RRI is an ambitious challenge for the creation of a Research and Innovation policy driven by the needs of society and engaging all societal actors via inclusive participatory approaches."

More specifically, the RRI framework consists of six key areas: (1) engagement, (2) gender equality, (3) science education, (4) open access, (5) ethics and (6) governance, the last one being an umbrella term for the first 5 areas. $^{2}$ On the website of the European Foundation Center the same first five areas of key relevance for RRI are also identified, area (6) on governance, however, is missing while they list science communication and career as two additional key areas of RRI. On this latter website, each key area is followed by short explanation. For instance, public engagement refers to the "engagement of people and civil society organizations in the research and innovation process and the integration of society in science issues" and careers to "making careers in science and technology attractive to young students". ${ }^{3}$

Two observations may be illuminating: First of all, it seems that most of these guidelines focus on what may be considered professional ethics or business ethics,

\footnotetext{
${ }^{1} \mathrm{http} / /$ ec.europa.eu/research/science-society/document_library/pdf_06/responsible-researchand-innovation-leaflet_en.pdf (Accessed 28 June 2013).

${ }^{2} \mathrm{http} / /$ ec.europa.eu/research/science-society/document_library/pdf_06/responsible-researchand-innovation-leaflet_en.pdf (Accessed 28 June 2013).

${ }^{3}$ http://www.efc.be/news_events/Pages/From-Science-in-Society.aspx (Accessed 28 June 2013).
} 
i.e. appropriate professional behavior in practices such as hiring or communicating. What appears rather neglected, in contrast, are the ethical implications of the epistemic practices in research and innovation themselves. Second, despite looming large in the title of the initiative, the term responsibility is surprisingly underrepresented in the descriptions of RRI's key areas and goals. In the summary on the website of the European Foundation Center the word "responsibility" is not to be found at all. In the leaflet by the European Commission, it appears at two instances: in the section on science education, it is argued that science education is needed to "equip future researchers and other societal actors with the necessary knowledge and tools to fully participate and take responsibility in the research and innovation process"4 while in the section on governance it says that "(p)olicymakers also have a responsibility to prevent harmful or unethical developments in research and innovation".

If RRI shall be of some use to tackle the challenges with respect to epistemic responsibility in a hyperconnected era, then we need to improve it on two fronts. First, we need to add some meat to the notion of responsibility, to fill the term "responsible" in Responsible Research and Innovation with some content. Second, when addressing epistemic responsibility in research and innovation, we need to focus on the ethics of epistemic practices themselves, i.e. the responsibilities of epistemic agents as epistemic agents.

When asking what it may mean to act responsibly as an epistemic agent within socio-technically entangled systems, I will become obvious that epistemic responsibility is a topic that links epistemology to ethics. Therefore, we do not merely a subsection on ethics in Responsible Research and Innovation: we need to understand and acknowledge — both in epistemic and in political terms - that epistemic practices are inherently ethical practices.

In the next sections, I will start addressing some of the challenges we face with respect to epistemic responsibility in a hyperconnected era.

\section{Approaching Distributed Epistemic Responsibility}

There are various research areas that have provided invaluable insights to crucial aspects of being responsible in knowing within entangled socio-technical epistemic systems. To open up this topic, I will in the following sections briefly introduce crucial insights from three different fields of research: research on epistemic responsibility in (social) epistemology, research on (distributed) moral responsibility in philosophy of computing, and research on distributed or entangled responsibility in feminist theory.

\footnotetext{
${ }^{4} \mathrm{http}: / /$ ec.europa.eu/research/science-society/document_library/pdf_06/responsible-researchand-innovation-leaflet_en.pdf (Accessed 28 June 2013).
} 


\subsection{Epistemic Responsibility: Insights from (Social) Epistemology}

Epistemic responsibility can be understood in terms of the duties of knowers in giving and accepting reasons. Within analytic epistemology, for instance, it is discussed whether and to what extent epistemic responsibility is a condition for epistemic justification and knowledge. Some theoreticians focus on very basic questions concerning our duties to revise beliefs in light of new evidence, fundamentally related to the topic of doxastic voluntarism, i.e. the question whether we can voluntary control our beliefs. Others address the question of what being a good informant implies (Craig 1990), focus on concepts of epistemic praiseworthiness and blameworthiness and relate epistemic responsibility to moral responsibility (Corlett 2008), or assess what our responsibilities are in granting authority to sources of information (Origgi 2008). While the topic of epistemic responsibility can be addressed with respect to different sources of knowledge, such as memory or perception, it is most interesting in the context of testimonial knowledge practices, i.e., practices related to receiving knowledge through the spoken or written words of others.

In recent years, testimony has emerged as a central topic within social epistemology, the philosophical discipline addressing the various ways in which knowledge is social. In contrast to the abundance of publications on testimony (e.g. Coady 1992; Fricker 2007; Adler 1994) and related topics such as epistemic trust (e.g. Origgi 2004; Simon 2010), epistemic authority (e.g. Origgi 2008), epistemic injustice (especially Fricker 2007), epistemic responsibility itself has only very recently attracted attention within analytic social epistemology. ${ }^{5}$

Although insights from social epistemology, in particular those addressing epistemic practices in more applied settings are highly crucial for a notion of epistemic responsibility for the 21 st century, there are several shortcomings: First and foremost, due to this origin in the debates around the epistemology of testimony, the focus of attention in this discourse of epistemic responsibility is also mostly on epistemic interactions between human agents, i.e. on the responsibilities of speakers and hearers in testimonial exchanges. Yet, taking into account that processes of knowing take place in increasingly entangled systems consisting of human and non-human agents, systems in which content from multiple sources gets processed, accepted, rejected, modified in various ways by these different agents, the notion of epistemic responsibility needs to be modified and expanded to account for such socio-technical epistemic processes. Two issues need to be addressed in more detail than is currently the case in most analytic accounts of epistemic responsibility: (a) the role of technology and (b) the relationship between power and knowledge. ${ }^{6}$ To

\footnotetext{
${ }^{5}$ Confer for instance the conference on "Social Epistemology and Epistemic Responsibility", which took place at Kings College in May 2012. http://www.kcl.ac.uk/artshums/depts/philosophy/ events/kclunc2012.aspx (Accessed 18 September 2013).

${ }^{6}$ It would be inadequate to argue that the role of technology or the role of power have been entirely neglected in social epistemology. On the one hand, there have been attempts to account for ICT
} 
put technology in general and ICT in particular into the equation, we should turn to philosophy of technology and philosophy of computing. Regarding the relationship between power, knowledge and technology, it has been feminist theoreticians in particular who have provided highly valuable insights. Thoughts from both fields will be briefly introduced in the next two sections.

\subsection{Responsibility \& ICT: Insights from the Philosophy of Computing}

The complexity and entanglement of social and technical compounds in many digital systems has lead to difficulties in locating agency, accountability and responsibility, which various philosophers of computing and computer ethicists aim to tackle. Unsurprisingly, there is a growing amount of research on moral and legal responsibility in computing (cf. Coleman 2004), specific foci being autonomous agents (e.g. Coeckelbergh 2009) and robotics (e.g. Pagallo 2010). With respect to accountability, Nissenbaum's (1997) paper on accountability in a computerized society is surely an early seminal piece, in which different causes for contemporary difficulties in accountability attribution are already worked out: the problem of many hands, the problem of bugs, using the computer as a scapegoat, and ownership without liability.

Of particular importance for the goals of this paper are Floridi and Sander's (2004) early considerations on the morality of artificial agents as well as Floridi's more recent analyses regarding distributed morality (Floridi 2012). According to Floridi and Sanders (2004) something qualifies as an agent if it shows interactivity, autonomy and adaptability, i.e. neither free will nor intentions are deemed necessary for agency. Such a concept of "mind-less morality" (Floridi and Sander 2004, p. 349) allows addressing the agency of artificial entities (such as algorithms) as well as of collectives, which may form entities of their own (such as companies or organizations). Another merit of their approach lies in the disentanglement of moral agency and moral responsibility: a non-human entity can be held accountable if it qualifies as an agent, i.e. if it acts autonomously, interactively and adaptively. However, it cannot be held responsible, because responsibility requires intentionality. That is, while agency and accountability do not require intentionality, responsibility does. Therefore, it seems that non-human agents - as long as they a) do not exhibit intentionality and $\mathrm{b}$ ) are considered in separation - cannot be held responsible even if they are accountable for certain actions.

(e.g. some works by Alvin Goldman (2008) and Don Fallis (2006), the special issue of the journal EPISTEME (2009, volume 6, issue 1, on Wikipedia). Moreover, Fricker's book on "Epistemic Injustice" (2007) has also stirred a lot of interest in the relationship between power and knowledge. However, these developments are rather recent and the classical assessment of testimonial processes remains focused on communication between humans often still conceived as an unconditioned and a-social subject $\mathrm{S}$, who knows that $\mathrm{p}$. 
While these considerations on responsibility and accountability in socio-technical systems are highly developed, the specific problem of epistemic responsibility in ICT has not yet been in the focus of attention within philosophy of computing. Hence, it appears worthwhile to take the best from both fields of research to develop a sound notion of epistemic responsibility within entangled socio-technical epistemic environments. Yet, instead of starting from scratch taking a look at feminist theory proves highly illuminating, because different feminist theoreticians have not only focused on the responsibilities of knowers in complex environments. They have also emphasized the important relationship between knowledge and power.

\subsection{Epistemic Responsibility in Entangled Socio-Technical Systems: Insights from Feminist Theory}

Despite the fact that epistemic responsibility has only very recently attracted attention within analytic epistemology, the term itself has already been used in 1987 as the title of a book by Lorraine Code (Code 1987). In this book, Code addresses the concepts of responsibility and accountability from a decidedly feminist perspective and argues that in understanding epistemic processes in general and epistemic responsibility and accountability in particular; we need to relate epistemology to ethics. Criticizing the unconditioned subject $\mathrm{S}$ who knows that $\mathrm{p}$, "the abstract, interchangeable individual, whose monologues have been spoken from nowhere, in particular, to an audience of faceless and usually disembodied onlookers" (Code 1995, p. xiv), Code emphasizes social, i.e. cooperative and interactive aspects of knowing as well as the related "complicity in structures of power and privilege" (Code 1995, p. xiv), "the linkages between power and knowledge, and between stereotyping and testimonial authority" (Code 1995, p. xv).

While Code's work highlights the relationship between knowledge and power, research by Karen Barad and Lucy Suchman adds technology to the equation and therefore appears particularly suited to explore the notion of epistemic responsibility within entangled and distributed socio-technical systems:

Barad's "agential realism" (Barad 1996; Barad 2007) delivers an "[...] epistemological-ontological-ethical framework that provides an understanding of the role of human and nonhuman, material and discursive, and natural and cultural factors in scientific and other social-material practices" (Barad 2007, p. 26).

Barad's approach is theoretically based upon Niels Bohr's unmaking of the Cartesian dualism of object and subject, i.e. on the claim that within the process of physical measurement, the object and the observer, Barad's "agencies of observation", get constituted by and within the observation process itself and are not pre-defined entities. The results of measurements are thus neither fully constituted by any reality that is independent of its observation, nor by the methods or agents of observation alone. Rather, all of them, the observed, the observer and the practices, methods and instruments of observation are entangled in the process of what we call "reality". For Barad, reality itself is nothing pre-defined, but something 
that develops and changes through epistemic practices, through the interactions of objects and agents of observation in the process of observation and measurement. Reality in this sense is a verb and not a noun.

Yet, interaction is a problematic term in so far as it presupposes two separate entities to interact. Thus, to avoid this presupposed dualism, she introduces the neologism of "intra-action", to denote the processes taking place within the objectobserver-compound, the entanglement of object and observer in the process of observation. This terminological innovation is meant to discursively challenge the prevalent dualisms of subject-object, nature-culture, human-technology, and aims at opening up alternative, non-dichotomous understandings of technoscientific practices.

A crucial concern of Barad is the revaluation of matter. Opposing the excessive focus on discourse in some other feminist theories, Barad emphasizes the relevance of matter and the materiality of our worlds. Taking matter serious and describing it as active, means to allow for non-human or hybrid forms of agency, a step that has been taken already with the principle of generalized symmetry in Actor-NetworkTheory. Yet, if we attribute agency to non-human entities, can and should they be held responsible and accountable? Plus, isn't that an invitation, a carte blanche to shirk responsibility by humans? Do we let ourselves off the hook too easily and throw away any hopes for responsible and accountable actions?

It appears that Barad's view on non-human agency and her stance towards the ontological symmetry between humans and non-humans has changed from earlier articulations (Barad 1996) to later ones (Barad 2007). In 1996, she still underscores the human role in representing, by stating that "[n]ature has agency, but it does not speak itself to the patient, unobtrusive observer listening for its cries - there is an important asymmetry with respect to agency: we do the representing and yet nature is not a passive blank slate awaiting our inscriptions, and to privilege the material or discursive is to forget the inseparability that characterizes phenomena" (Barad 1996, p. 181).

However, it seems that this special treatment of humans and especially the notion of representing does not well match her posthumanist performativity, as depicted some years later (Barad 2003). Finally, in "Meeting the Universe Halfway" Barad offers a more nuanced dissolution of the distinction between human and non-human agency. By stating that "[a]gency is a matter of intra-acting; it is an enactment, not something that someone or something has" (Barad 2007, p. 261), Barad moves the locus of agency from singular entities to entangled material-discursive apparatuses. But even if agency is not tied to individual entities, it is bound with responsibility and accountability, as Barad makes very explicit: "Learning how to intra-act responsibly within and as part of the world means understanding that we are not the only active beings - though this is never justification for deflecting that responsibility onto other entities. The acknowledgment of "nonhuman agency" does not lessen human accountability; on the contrary, it means that accountability requires that much more attentiveness to existing power asymmetries (Barad 2007, p. 218 f).

Thus, the possibility to understand agency not essentialist as a (human) characteristic, but as something which is rather attributed to certain phenomena within 
entangled networks could be regarded as an invitation to shirk of responsibility. But this is clearly not the aim of Barad. When developing her posthumanist ethics, Barad concludes that even if we are not the only ones who are or can be held responsible, our responsibility is even greater than it would be if it were ours alone. She states: "We (but not only "we humans") are always already responsible to the others with whom or which we are entangled, not through conscious intent but through the various ontological entanglements that materiality entails. What is on the other side of the agential cut is not separate from us - agential separability is not individuation. Ethics is therefore not about right response to a radically exterio/ized (sic!) other, but about responsibility and accountability for the lively relationalities of becoming of which we are a part" (Barad 2007, p. 393).

This focus on responsibility and accountability relates back to Barad's initial framing of agential realism as an "epistemological-ontological-ethical framework", a term by which she stresses the "[...] fundamental inseparability of epistemological, ontological, and ethical considerations" (Barad 2007, p. 26). Barad insists that we are responsible for what we know, and - as a consequence of her onto-epistemology for what is (Barad 2003, p. 829). Accountability and responsibility must be thought of in terms of what matters and what is excluded from mattering, what is known and what is not, what is and what is not.

This acknowledgement that knowledge always implies responsibility, not only renders issues of ethics and politics of such knowledge- and reality-creating processes indispensable. It also relates directly back to Barad's emphasis on performativity: epistemic practices are productive and different practices produce different phenomena. If our practices of knowing do not merely represent what is there, but shape and create what is and what will be there, talking about the extent to which knowledge is power or entails responsibility gets a whole different flavor.

Lucy Suchman shares many concerns of Karen Barad and her insights promise to be of particular importance for considerations regarding computationally mediated environments due to Suchman's background in Human-Computer Interaction. Acknowledging the relational and entangled nature of the sociomaterial, Suchman claims that agency cannot be localized in individual entities, but rather is distributed within socio-material assemblages. Resonating with Barad, she notes "[...] agencies - and associated accountabilities - reside neither in us nor in our artifacts but in our intra-actions" (Suchman 2009, p. 285).

The question, however, remains how exactly to be responsible, how to hold or to be held accountable if agency is distributed. How can we maintain responsibility and accountability in such a networked, dynamic and relational matrix? Although I think that Suchman goes into the right direction, she remains quite vague about this in her concluding remarks of Human-Machine-Reconfigurations by stating that "responsibility on that view is met neither through control nor abdication but in ongoing practical, critical, and generative acts of engagement. The point in the end is not to assign agency either to persons or to things but to identify the materialization of subjects, objects, and the relations between them as an effect, more and less durable and contestable, of ongoing sociomaterial practices" (Suchman 2009, p. 285). 


\section{Facing Distributed Epistemic Responsibility}

To understand the epistemic responsibilities of knowers in our contemporary, hyperconnected world, I think all insights outlined above need to be accounted for. Yet it still has to be explored and discussed in detail a) whether, how and to what extent they can be aligned and b) what the implications both on an individual and a governance level could or should be. That means that we need conceptual advancements as well as practical solutions and guidance both for individuals and policy makers. Before I turn to both tasks, let me recapitulate the challenges regarding epistemic responsibility in our hyperconnected era.

As knowers we move and act within highly entangled socio-technical epistemic systems. In our attempts to know, we permanently need to decide when and whom to trust and when to withhold trust, when to remain vigilant. Loci of trust in these entangled and highly complex environments are not only other humans, but also technologies, companies, or organizations - and they usually cannot be conceived in separation but only as socio-technical compounds. This holds true for our daily life, imagine just the case of someone booking a flight online. It holds even more true for scientific environments, where information acquisition and processing involve various hyperconnected agents and institutions.

Socio-technical epistemic systems are highly entangled but also highly differentiated systems consisting of human, non-human and compound or collective entities each equipped with very different amounts of power. To understand this, search engines are a useful example. In highly simplified terms, search engines can be conceived as code written, run and used by human and non-human agents embedded in socio-technical infrastructures as well as in organizational, economic, societal and political environments. While there are potentially many ways to enter the World Wide Web, search engines have emerged as major points of entrance and specific search engines nowadays function as "obligatory passage points" (Callon 1986), exerting tremendous amount of not only economic, but also epistemic power.

That is to say that the fact that both human and non-human entities can qualify as agents does not imply that we have entered a state of harmony and equality: there are enormous differences in power between different agents. To use Barad's terminology, some agents matter much more than others. And - for better or worsethose that matter most do not necessarily have to be human agents.

In Actor-Network-Theory (e.g. Latour 1992; Law and Hassard 1999), power is conceived as a network effect - a view that is highly plausible and useful in the context of search engines, recommender systems or social networking sites, because the power of specific search engines does not stem from any a priori advantage, but rather is the result of collective socio-technical epistemic practices in which we all are involved: it is our practices of knowing, of relying on and using information which influence and shape the power distributions in our environment.

It is in these sociotechnical, hyperconnected and entangled systems, that the notion of epistemic responsibility is becoming a key challenge for both policy makers and us as individual epistemic agents processing information in research just as much as in our every-day lives. 


\subsection{Re-Conceptualizing Epistemic Responsibility}

Responsibility is a rich concept, a concept with many nuances, a noun that changes its meaning if coupled with different verbs. There is a difference between being responsible and taking responsibility: we can be responsible for something, but deny assuming responsibility for it. This temptation to shirk responsibility is probably as old as humankind and has lead to sophisticated techniques in cutting down chains of responsibilities in law or the insurance sector. On the other hand, we may also accept the full responsibility for something, even if we are not, or at least only partially responsible. If a minister steps back, because of some misconduct in her ministry she has not even been aware of, she takes responsibility, she responds. Moreover, responsibility can be assumed oneself as well as attributed to someone else.

All these different meanings of responsibility and their intersections are crucial for understanding what it takes to be epistemically responsible in socio-technical environments consisting of human and non-human agents. For instance, before asking for criteria of how exactly responsibility can be assumed or attributed and further how it should be assumed or attributed, we may start by asking these two related but distinctive basic questions that are of increasing relevance in our computational age: (1) Can epistemic responsibility be assumed only by human agents or also by other agents? (2) Can epistemic responsibility be attributed to only human or also non-human agents?

As a first step to apprehend these questions, I suggest disentangling the notions of agency, accountability and responsibility more carefully. Both Barad and Suchman seem to use the terms responsibility and accountability interchangeably. However, taking some philosophical insights into account, it seems fruitful to maintain a distinction between these two notions. As noted before, for Floridi and Sanders (2004), agency requires interactivity, autonomy and adaptivity, but no intentionality is needed. Accountability is bound to agency only and hence also does not require intentionality of agents. However, responsibility differs from accountability exactly by requiring intentionality. Hence, if we agree with Floridi and Sanders (2004) that responsibility as opposed to agency and accountability requires intentionality, then it makes no sense to talk about responsibility with respect to technical artifacts. A car cannot be made responsible for a crash, it is the driver who is to blame-for negligence or ill-will - or maybe the manufacturer, if a technical flaw caused the crash. If an unmanned vehicle that drives autonomously, interactively and adaptively caused a crash, this car may be accountable for a crash, but it cannot be held responsible. Please note that it is only the technical artifact in isolation, which cannot be made responsible. For socio-technical compounds, the possibility of attributing responsibility would still be given, hence this perspective may in the end well be compatible with Barad's agential realism (Barad 2007).

To my mind, the distinction between accountability and responsibility is crucial and I think we need a strong concept of responsibility reserved for intentional agents to really account for Barad's insights regarding the entanglement between (a) the social, the technical and the epistemic, as well as (b) between epistemology, ontology and ethics. Reconsider the core distinction between being responsible and 
taking responsibility: while Barad rightly stresses our interdependences (or rather intradependences), the entanglement of human and non-human agents in knowing, being and doing, the process of assuming responsibility is and remains an intentional act.

For epistemic responsibility this means that as responsible epistemic agents, we intentionally assume responsibility for what we claim to know. In full awareness of our socio-technical epistemic entanglement, we accept to be challenged for what we claim to know, we commit ourselves to provide evidence for our claims and to revise our beliefs in the light of new evidence. Hence, to understand and improve our processes of knowing, to be responsible knowers as individuals, we first need to acknowledge both the deep entanglements between the social, the technical and the epistemic as well as between epistemology, ethics and ontology. However, the only adequate reaction to this awareness must be to assume responsibility as an intentional act. It is only we humans (so far?) that can take this stance, hence it is our duty to assume responsibility for our interrelated ways of knowing, being and doing.

However, what is also clear is that the ease with which epistemic responsibility can be assumed differs between different socio-technical environments: in some environments assuming responsibility for what one knows is rather easy, in others it is much more difficult. Access to various types of evidence, to supporting or contradicting information is essential to become epistemically responsible in knowing. It is in this sense that supporting open access is a very important and valid aspect of Responsible Research and Innovation. More generally it means that our individual efforts must be complemented with appropriate policies that support environments in which epistemic responsibility assumption is enabled, fostered and incentivized.

\subsection{Governance for Epistemic Responsibility}

Based upon conceptual work regarding the basic meaning of concepts such as responsibility, accountability, action or intentionality, we need to come up with practical solutions to support responsibility assumption and attribution in our hyperconnected reality from a governance perspective. We need to develop policy frameworks that enable and support epistemically responsible behaviour.

How would such frameworks to be conceptualized? Take the example, I have given before, Responsible Research and Innovation (RRI), which is clearly meant to offer guidance for designing and governing environments that elicit and support responsible epistemic practices. Yet despite its name, Responsible Research and Innovation, as currently conceived, cannot fulfill these tasks properly because it fails tackling important challenges worked out in this contribution, namely a) to properly acknowledge the socio-technical entanglement of knowers, $b$ ) to properly acknowledge the interdependency of epistemical, ontological and ethical aspects of science, c) to support responsibility assumption and attribution and d) to be attentive to power asymmetries within entangled socio-technical environments. 
Hence, in order to really enable and support epistemic responsibility it would be essential to revise and amend current the RRI guidelines by adding new guiding thoughts such as the following:

1. Acknowledge the interrelation of epistemology, ethics and ontology: knowing, doing and being are interrelated, i.e. our processes of knowing have effects on what can be done and what we are - and vice versa.

2. Keep in mind the deep socio-technical entanglement of contemporary epistemic practices: Within our practices of knowing, we depend upon other human and non-human agents just as much as these other agents depend on us.

3. Bear in mind that epistemic relations are power relations: Within socio-technical epistemic systems, different epistemic agents, human as well as non-human agents, such as algorithms, are equipped with different amounts of power. 4. ... etc

Thus, if revised appropriately, RRI could provide guidance on how to act responsibly in research and innovation as particularly knowledge-intense domains. Yet epistemic practices exist beyond research and governance supporting epistemic responsibility accordingly has to be expanded beyond advice or regulations regarding research and innovation. Each and every one of us has to assume epistemic responsibility for the things we claim to know in our everyday life as well. When and whom should we trust to know about climate change, about the war on terrorism or just about the latest unemployment numbers? How vigilant do we have to be when accepting information received from various on- and offline sources?

While these are challenges that we all face on a daily basis, they also pose challenges for the governance of socio-technical epistemic systems. In a computational age characterized by ever more powerful personalization and profiling techniques assuming epistemic responsibility becomes much harder, because we may neither be able to decide which information we receive nor which information is received about us. After all, how can we be responsible knowers if we cannot assess how trustworthy our sources of knowledge are?

Without denying the utility of personalized services, in order to act epistemically responsible in an age of extensive profiling and personalization, we need the possibility to access, understand and to even trick the systems which are accessing, understanding and potentially tricking us. As Mireille Hildebrandt stresses in her contribution, we need to develop "first (...) human machine interfaces that give us unobtrusive intuitive access to how we are being profiled, and, second, a new hermeneutics that allows us to trace at the technical level how the algorithms can be 'read' and contested" (Hildebrandt 2013). We need policies addressing more broadly the challenges related to distributed epistemic responsibility in a hyperconnected reality, policies to set the parameters for an environment where individuals can act responsibly, i.e. where they can both assume and attribute responsibility even if they are deeply socio-technically entangled.

To conclude: in the long run, it will be essential to develop a concept of epistemic responsibility that can account for the responsibilities of various differently empowered agents within entangled socio-technical epistemic systems. Moreover, 
we will need to develop policy frameworks that provide guidance both for the individual seeking to act responsibly in knowing and for the design and governance of environments that support epistemically responsible behaviour. In addition to the goals that Pagallo has described for his notion of "good enough Onlife governance" (Pagallo 2013), these frameworks should entail support for individuals (e.g. education and support of digital literacy) as well as incentives for the research and design of epistemically beneficial systems (e.g. transparency-by-design, research on better interface design, development of tools for argumentation extraction and visualization, etc.). ${ }^{7}$

Open Access This chapter is distributed under the terms of the Creative Commons Attribution Noncommercial License, which permits any noncommercial use, distribution, and reproduction in any medium, provided the original author(s) and source are credited.

\section{References}

Adler, J. 1994. Testimony, trust, knowing. The Journal of Philosophy 91 (5): 264-275.

Arendt, H. 1958. The human condition chicago. Chicago: The University of Chicago Press.

Barad, K. 1996. Meeting the universe halfway. Realism and social constructivism without contradiction. In Feminism, Science, and the Philosophy of Science, ed. L. H. Nelson and J. Nelson, 161-194. Dordrecht: Kluwer.

Barad, K. 2007. Meeting the universe halfway: Quantum physics and the entanglement of matter and meaning. Durham: Duke University Press.

Barad, K. 2003. Posthumanist performativity: Toward an understanding of how matter comes to matter. Signs: Journal of Women in Culture and Society 28 (3): 801-831.

Callon, M. 1986. Some elements of a sociology of translation: Domestication of the Scallops and the Fishermen of St Brieuc Bay. In Power, Action and Belief: A New Sociology of Knowledge, ed. J. Law, 196-233. London: Routledge \& Kegan Paul.

Coady, C. A. J. 1992. Testimony. A philosophical study. Oxford: Claredon Press.

Code, L. 1987. Epistemic responsibility. Hanover: University Press of New England.

Code, L. 1995. Rhetorical spaces: Essays on gendered locations. New York: Routledge.

Coeckelbergh, M. 2009. Virtual moral agency, virtual moral responsibility: On the moral significance of the appearance, perception, and performance of artificial agents. AI \& Society 24 (2): $181-189$.

Coleman, K. G. 2004. Computing and moral responsibility. Stanford encyclopedia of philosophy. http://plato.stanford.edu/entries/computing-responsibility/. Accessed 28 June 2013.

Corlett, J. A. 2008. International Journal of Philosophical Studies 16 (2):179-200

Craig, E. 1990. Knowledge and the State of Nature: An Essay in Conceptual Synthesis. Claredon Press, Oxford.

Fallis, D. 2006. Social epistemology and information Science. Annual Review of Information Science and Technology 40:475-519.

Floridi, L. 2012. Distributed morality in an information society. Science and Engineering Ethics, 19 (3): 727-743.

\footnotetext{
${ }^{7}$ This research was supported by the Austrian Science Fund (P23770) and the Karlsruhe Institute of Technology.
} 
Floridi, L., and J. W. Sanders. 2004. On the morality of artificial agents. Minds and Machine 14:349-379.

Fricker, M. 2007. Epistemic injustice. Power and the ethics of knowing. Oxford, Oxford University Press.

Goldman, A. I. 2008. The social epistemology of Blogging. In Information Technology and Moral Philosophy, ed. J. v. d. Hoven and J. Weckert, 111-122. New York: Cambridge University Press.

Hildebrandt, M. 2013. Onlife, the public(s) and legal protection by design. The onlife manifesto. https://ec.europa.eu/digital-agenda/sites/digital-agenda/files/Contribution_Mireille_Hildebrandt.pdf. Accessed 28 June 2013.

Law, J., and J. Hassard, Eds. 1999. Actor Network and After. Oxford: Blackwell.

Latour, B. 1992. Where are the missing masses? The sociology of a few Mundane Artifacts. In Shaping Technology/Building Society: Studies in Sociotechnical Change, ed. W. E. Bijker and J. Law, 225-258. Cambridge: MIT Press.

Nissenbaum, H. 1997. Accountability in a computerized society. In Human values and the design of computer technology, ed. B. Friedman, 41-64. Cambridge: Cambridge University Press.

Origgi, G. 2004. Is trust an epistemological notion? Episteme 1 (1): 1-12.

Origgi, G. 2008. Trust, authority and epistemic responsibility. Theoria 61:35-44.

Pagallo, U. 2010. Robotrust and legal responsibility. Knowledge, Technology \& Policy 23 (3-4): 367-379.

Pagallo, U. 2013. Good onlife governance: On law, spontaneous orders, and design. https:// ec.europa.eu/digital-agenda/sites/digital-agenda/files/Contribution_Pagallo.pdf. Accessed 28 June 2013.

Simon, J. 2010. The entanglement of trust and knowledge on the Web. Ethics and Information Technology 12 (4): 343-355.

Suchman, L. A. 2009. Human-machine reconfigurations. Plans and situated actions. Cambridge: Cambridge University Press. 